\title{
Model for teaching a foreign language class based on the principles of chaos/ complexity theory
}

\author{
Hanieh Davatgari Asl ${ }^{1}$, Fahime Farjami ${ }^{2}$, Muhammad Makhdoumi ${ }^{1}$ \\ ${ }^{1}$ Department of English Language Teaching, Ahar Branch, Islamic Azad University, Ahar, Iran \\ ${ }^{2}$ Young Researchers and Elite Club, Ahar Branch, Islamic Azad University, Ahar, Iran
}

\section{Email address:}

hdavatgar@yahoo.com (H. D. Asl), fahimefarjami@yahoo.com (F. Farjami),mmakdoumi@gmail.com (M. Makhdoumi)

\section{To cite this article:}

Hanieh Davatgari Asl, Fahime Farjami, Muhammad Makhdoumi. Model for Teaching a Foreign Language Class Based on the Principles of Chaos/ Complexity Theory. International Journal of Language and Linguistics. Special Issue: Foreign Language Teaching and Learning (Models and Beliefs). Vol. 2, No. 3-1, 2014, pp. 32-41. doi: 10.11648/j.ijll.s.2014020301.14

\begin{abstract}
Chaos/complexity theory first appeared in studies of the natural sciences like physics and mathematics over 50 years ago. This up to date theory has been used in different fields to study complex systems, including social studies particularly the study of language and second language acquisition. Language learning in an instructional context is complex, chaotic, dynamic, open, nonlinear, self- organizing, adaptive, sensitive to initial conditions and creates fractals, strange attractors and feedback. In this study the present researcher has thought of applying chaos/complexity features into teaching second language class. The aim of this study is to familiarize English teachers with chaos/ complex theory and have a greater awareness of this up to date theory of pedagogy. At least forty theories of SLA have been proposed, but none of them gives a complete explanation of this complete process. Complexity theory takes into account all factors and may offer a sound language teaching model. In a training session, the researcher introduced the features of chaos/complexity theory in SLA to English teachers and also provided some practical educational implications to use into their teaching practice. Finally teachers' feedback and attitudes were analyzed through content analysis and grounded theory to see whether their feedback and opinions are positive or negative. Chaos theory produces a multidimensional classroom that students and facilities interact. The language class context is exactly mirrored by 15 features, which emphasized the elements in natural system. And finally, students will learn how to learn, how to live pleasantly and will be empowered by English language.
\end{abstract}

Keywords: Chaos/Complexity Theory, Content Analysis, TEFL, SLA

\section{Introduction}

Chaos/complexity theory first appeared in studies of the natural sciences like physics and mathematics over 50 years ago (1950).Experts from various fields have used and held this theory as an up to date way in which we can study the different complex systems in the world, including social studies especially the study of language and second language acquisition. The language class is like other natural complex systems in the world that can be studied from this new view because it shows many similar features of chaotic /complex systems. Language learning in an instructional context is not only complex, chaotic, dynamic, open non-linear, self- organizing, adaptive, feedback, sensitive to initial conditions but also it creates fractal and strange attractors.
Chaos /complexity theory is not completely modern concept, as its parts have emerged in various cultures and branches of thought throughout the entire history. Konrad Lorenz applied chaotic principles to describe weather phenomena during the 1950s.Mathematics accompanied with improvement in computer technology showed the wonderful patterns which emanate from an appealingly random set of numbers produced by complex, nonlinear equations in the 1970s. In the 1980s, astronomers as well used parts of the theory to solve some riddles of planetary and lunar complex orbits caused by the feedback influences of gravity in solar system.

In this study the present researcher shortly defines these features in nature, language and second language acquisition and tries to explain how he is interested to apply these characteristics to teaching practice. The researcher has also thought of applying chaos/ complexity 
features into his English language lessons and provides a model of teaching second language class based on this theory.

\section{Statement of the Problem}

At least forty theories of SLA have been suggested (Larsen- Freeman \&Long, p227), but none of them tries to give SLA a complete explanation for this complex phenomenon and just focus on syntactic structure acquisition and do not pay attention to other underlying aspects. Therefore we need a theory that takes into account all these factors, offers a language teaching model based on this theory. (Menezes, 2008).

\section{Significance of the Study}

. As language influences our way of thinking, teachers, who will be familiar with the features and terminology of chaos and complex theory will be more aware of what occurs in their language classrooms and be capable to reflect on their teaching practice with this new, promising teaching framework.

\section{Purpose of the Study}

The present study aims to explain and represent complexity involved in English language classroom to English teachers who do not have any information of chaos/ complex theory. In a teacher training session, about 45 minutes, the researcher will introduce the features of chaos/complex theory in SLA to English teachers as well as familiarize the participants with the similarities, connections between chaos/complex theory features and teaching.

\section{Review of Literature}

\subsection{Science and Myths}

Man has always tried to explain the world first by different myths, then by way of science. Armstrong (2005, p3) states "Mythology and sciences both expend the scope of human beings". Lakoff and Johnson (1980) explain that myths like metaphors, are necessary. It is very interesting that chaos theory is taken from Greek mythology. Chaos theory suggests a way of viewing the world and everything in it. Chaos can be viewed as a replacement for the metaphor of clockwork predictability proposed by Newton that world is not governed by simple rules such as a clock, but it is made of complicated and connected systems.

Waldrop(1993,p 330)declared chaos theory metaphor describes the world as "a kaleidoscope: the world is a matter of patterns that change, that partly repeat, but never quite repeat, that are always new and different". Chaos theory has been used in different fields to explain different phenomena including knowledge dynamics and SLA
(Larson-freeman, \&Cameron, 2008; Masseh and Weingart, 2000)

There are many similarities between SLA and theories and creation myth .In different cultures, creation myths begin with an initial emptiness or chaos, so do SLA theories. In Christen genesis, the world was created from a formless state, like the structuralists that claim that SLA develops from an initial formless state through addition of structures. In Chinese creation mythology, the universe is described as a black egg that was mixed together with heaven and earth.

Van Lier (2004) cited in (Menezes, 2008) had a perspective and argued that chaos/complex theory has the following features.

1. Encourages a blurring of boundaries and dichotomies.

2. Warns against setting for simple solutions prematurely, as well as against rejecting contrasting viewpoints.

3. Provided some fresh light on SLA phenomena.

4. Refocuses our attention in the light of emergent phenomena, foregrounding certain problems, and obviating others.

\subsection{Chaos Theory Applications in Different Fields}

Chaos theory is used generally in mathematics and has a lot of applications in physics, engineering, economics and biology and soon. It studies dynamic systems that are very sensitive to their initial conditions. For example, small differences (like rounding error in numerical computations) produce very drastic results and make long term prediction generally impossible. In many natural systems, for example weather, jungle, desert, chaotic behavior can be observed. Chaos in common usage means "a state of disorder", but in chaos theory, it has been defined more exactly. Chaos is applied in many disciplinary like: geology, economics, finance, psychology, physics, politics, robotics, philosophy, mathematics, population dynamics, biology, microbiology, meteorology. It has also been used in works of literature and movies including Jurassic Park based on Michael Crichton's novel. Chaos theory was the object of the BBC documentary "High Anxiety".

\subsection{The General Features of Complex, Nonlinear, Dynamic Systems in Nature}

Everything that is natural and real is also chaotic like: deserts, space flight, the stock market, electronic circuits, national economies, and ecology of jungles etc. The list of natural and chaotic system is endless. As students behave more naturally and positively, and learn more efficiently in a more natural setting.

A dynamic system has the following characteristics: They are chaotic, unpredictable, sensitive to initial conditions, dynamic, complex, non-linear, strange attractors, strange fractors, fractal shape, open, selforganizing, feedback, adaptive, attractors, bifurcation, the edge of chaos. 
Chaos: is the period of complete randomness that complex systems enter into unpredictably. An example is this concept of water dripping from a spigot, with a slight twist of a faucet, the water falls in a regular, even drip. Given slightly more pressure, the drops, while still falling separately, fall in a new- repeating pattern. The periodic drip has given way to a random- seeming pattern (Crutch field, Palmer, Packard, \& Shaw, 1986).

Unpredictable: The starting point of randomness of complex systems is unpredictable. The fact that randomness will occur is foreseeable, but when it will happen is not predictable. Avalanches are made by sliding rock, but it is absolutely impossible to predict which rolling pebble will set free a glide slide. The nonlinear systems work in a regular, usual way until a critical point, then they go chaotic unpredictably, they may turn to order (Briggs, 1999, p 19-20)

Sensitive to initial conditions: An important cause for unpredictable conduct of complex systems is their sensitive dependence on initial conditions. A very minute change in initial condition can have huge implications for future behavior of the system. In fact, the workings of systems with various initial conditions will diverge tremendously as the time passes.

The butterfly effect is a phenomenon which is a good exemplification of this feature and underlines the interconnections of all existing parts in the complex system. The butterfly effect is a concept that indicates that a butterfly which flutters its wings in a very far part of the world today can change the local weather configuration next week or next month. It was called this because of the title of a paper by Edward Lorenzo in 1972: Does the Flap of a Butterfly's Wings in Brazil set off a Tornado in Texas? The flapping wing shows a small change in the system, which leads it to a different larger- scale phenomena. The trajectory (direction) of the system might have been extraordinary different, if the butterfly had not flapped its wings.

Camel back effect is also a proverb used to show this butterfly effect, which literary means that it is the last straw that breaks the camel's back. This proverb expresses the idea that a small thing can cause a big effect usually a negative effect. Gleik (1987, p 8) postulates that minute differences in input could become outstanding differences in output. Sensitivity to initial conditions means each end point in a system is randomly approximated by other points with prominently various future trajectories.

The notion of butterfly effect is exemplified with folklore in the following way:

For want of a nail, the shoe was lost.

For want of a shoe, the horse was lost.

For want of a horse, the rider was lost.

For want of a rider, the battle was lost.

For want of a battle, the kingdom was lost.

The loss of a nail destabilized the kingdom and led to its loss. The same point of crisis may happen in the chaotic system of a classroom. The teachers' attitudes or choices may help one student to win and the other to lose. For example, students may react differently to teachers who don't believe in them. Students may feel extremely discoursed and one may be challenged and succeed.

Natural forms ( clouds, mountains, ferns, trees, deserts_ may be reproduced through an iterated function system(IFS).The electronic computer was the most catalyst for evolution of chaos theory, because mathematics involves the repeated iteration of simple formulas, which is hard to perform by hand. These repeated calculations were made practical by electronic computers, whereas images and figures made it easy to visualize these complex systems.
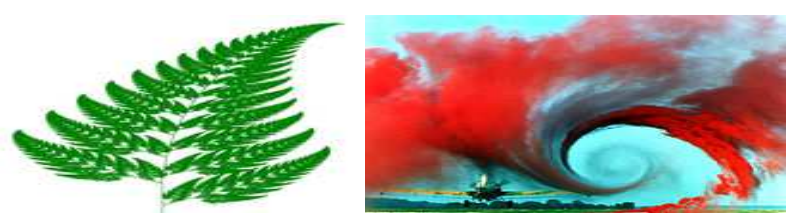

Figure 1. Turbulence from an airplane wing and natural form of a fern may be recreated through an (IFS).

Dynamic: Chaos theory or dynamic systems theory (Abraham, 1994), Plectics (Gell Mann in Berreby, 1994), catastrophe theory (Thom, 1972) and complexity theory are all related with the dynamic behavior i.e. systems that change over time. As Gleik (1987, p 5) refers to it as the study of "chaos is a dynamic science of process rather than state, of becoming rather than being".

Complex: The study of the behavior of dynamic systems is not very modern in science. The innovation is that their center of focus is complex systems. The two reasons that they are called complex are: First, complex systems often comprise of a large number of parts or agents (Davies, 1988, p 22).For instance, the human brain consisted of billions of related neurons. Second, behavior of dynamic complex systems is more than a by- product of the working of its distinct individual components.

Nonlinear: A nonlinear system means that effect or result is disproportionate to the cause. A case of minute strength results in an effect of equal strength in a linear system. But in nonlinear systems it is not always the case. Their effect may be out of proportion to the cause. For example, a rolling pebble, in a mountain, can produce a great avalanche. This has been called the camel's back effect or butterfly effect. A simple, regular trigger can cause a great chaos in the system.

Strange attractor: The path that a complex, dynamic system travels and takes can be traced in location or space is called an attractor. It is called because it is the usual pattern to which a whole dynamic system is attracted. For instance, a bob swinging on the end of a string has a fixed attractor point, at last the bob will settle down (i.e. stop) and will be attracted to the fixed point if the there is no influx of energy. On the other hand, a frictionless pendulum has a periodic attractor. Its attractor is an orbit defined by two extreme ends. 
Open: The second law of physics, thermodynamics, states that systems necessary move towards equilibrium. "And once a system reaches this equilibrium state, this lowest state, it tends to stay there forever with no pattern, no form, and no differentiation". Churchland (1988, p. 168) But Helmholtz, German physicist (1854) concluded that entire universe would finally would stop or increase in entropy i.e. a complete lack of order in a system. Biologists studying the development of living systems observed that living systems were evolving from disorder to order. For example natural selection has been the only source of that order. The large scale structuring in the systems counter the entropy forces and create order and structure(Smith and Gemmil, 1991).However, how order emerges from entropy (complete disorder) in nature is the most paramount problem in science of chaos and complexity.

Self- organizing: Scientists believe that the second law of thermodynamics applies to closed systems. In open systems that new emerging and matter come into the system, entropy (disorder) is not necessary because open systems evolve and develop in order and complexity by attracting energy. For example, highly organized states, like, advanced human brains, can suddenly pop up, or take another example of self-organizing system, in which light particles group themselves into a very powerful beam.

Feedback sensitive: The order that such complex systems demonstrate is created by the truth that they are sensitive to feedback. Maybe this feedback sensitivity is really understood in Darwin's' natural selection which shows existence of basic feedback working. The steady development of a species was called evolution (Waldrop, 1992.P 179), Briggs (1992, p 117) declared that mutation changes and keeps the design of the species stable for long periods of time".

Adaptive: The capacity of complex, nonlinear systems in biology to naturally select and self-organize is called adaptively. (Kauffman, 1991) Complex systems are not passive to events; they attempt to take advantage of whatever occurs. Berry (1994, p 26) points out that "organisms have the capacity of learning, always test a part of their behaviors against reality and modify it to be suitable and occurs at various time scales throughout biology"

\subsubsection{The Edge of Chaos}

The critical point.i.e.the point of crisis is called the edge of chaos.Waldrop(1993, p147) states that complex systems are " always unfolding, always in transition, in fact, if the system ever does reach the equilibrium, it is not just stable. It is dead"Morever according Waldrop (1993, p12) the edge of chaos is delinated as " the ability to bring order and chaos into a special kind of balance". It is a phase of maximum potential creativity where the system works between chaos and order. It is aphase where stability gives way to transformation and creativity.

Complex learning system moves to the edge of chaos because equilibrium means the death of the system. For example, those learners who end up their attempts to learn the language have gained equilibrium.

\subsubsection{Bifurcation}

A point that a critical decision or choice is made. For example it is to study this field or another field. To continue to learn or to give up learning. Or the system of a learner may bifurcate towards the acquiring of another complex language system.

When a learner goes to a new challenging school, he/she is perturbed and moves to a chaotic attractor inside the complex school system. The challenging requirements of English school program makes a butterfly effect (Camel back or avalanche effect) and the student may be unexpectedly attracted by another language program in which he/she will succeed. In the first language program, it is a failure for him but for the second language program it is a success for him/her.

The classroom is not the perfect idealized "cooperative paradise" that teacher may dream of about it, but a place that some learners protect their identities against their teachers and partners. Despite of that, when learners reach their edge of chaos, new behaviors may emerge. In the complex learning system, the important notions of individuality, identity, agency and autonomy should be taken into account. The autonomous students will find their ways out, to overcome barriers and construct their identity as second language speakers.

Successful learners are active and take challenging risks, explore and experiment the learning environment. Chaos brings uneasiness in the SLA process, but it gives individual language learners a lot of affordances and opportunities to become independent learners and be aware of their agency, creativity to construct their SL speaker identity.

\subsection{Features of Complex, Nonlinear systems and Language}

There are many similarities between complex nonlinear system and the study of language. Whereas language can be explained as accumulation of paradigmatic and syntagmatic units like: phonemes, morphemes, sentences, paragraphs, etc., a dynamic view of language can be accepted .Saying that language is dynamic has three meanings.

First, language is a process. Although language is a collection of static units or products, but its real speech involves an active process that is usually called as parole by Saussure or performance by Chomsky (Larsen-Freeman, 2008).

Second, the other usual way that language is understood to be dynamic is when dynamisms is equal to growth and change. Rutherford (1987, P37) suggested that organism is a better metaphor for language than a machine, because machines are constructed, but organism grow. Rutherford's proposal regards language as one of the natural organisms of world which operates according to the methods of 
natural sciences. Language has its periods of growth, maturity, decline, independently of its speakers' will. (Robins, 1967). Bloor and Pinker (1990) employed the biological metaphor of evolution. If language is seen not only from a synchronic but also from a diachronic view, is surely dynamic.

Nonlinear: The changes that world languages undergodiachronically are nonlinear and complex .New words and forms entered the language.

Chaotic behavior: A synchronic snapshot of language may seem chaotic, because different speakers of the language using various forms to mean the same thing.

Unpredictable: Which new forms of language entered into the language is absolutely unpredictable. We can foresee changes somewhat by saying that new inventions, innovations developments in technology, come up by an expansion of words or lexis to talk about new concepts or products. When there is some insecurity on the part of native speakers, for example, the choice between using subject and object pronouns in English. English speakers use reflexive pronouns for both subject and object pronouns. Between you and myself or Alex and myself went. We can explain language change a posteriori, because we cannot make exact predictions of what change will happen next.

Dynamic: The word of dynamic means diachronic growth/change and synchronic explains the complex systems. Dynamicview looks at how language is usually constructed and made. The feature makes no distinction between present use and change, because both of them are isomorphic and complex process. Every time a language is used, it changes. As I write this sentence about chaos theory and as you read it, both of us are changing English language rather than using different rules to shape the language discourse and the rules are shaped by the discourse context.

Fractal: Just as complex nonlinear systems, so language is afractal. As Taylor (1994, p 203) declared it is language fractality that makes accessible an infinite rate of behavior or information, within a closely restricted space". An example of fractality of language is connecting word rank and word frequency for many world natural languages. In other words, if a word occupies a specific word frequency rank in a given language, then it is likely to reflect that same frequency in any given text of that language. In sum, changes are happening consistently and these changes are reflected at every level of scale. Diller(1995,p 117) points out that " the conduct of the systems as a whole is the results of the co-working of local interactions, Thus a language such as English is a collaborative effort of its speakers, changes in the system of English that are emergent".

Self-organize: Language develops and organizes itself from bottom up in an organic way as do other complex nonlinear systems. To understand the dynamics of this "bottom-up" approach, computer scientists have tried to change the way to represent the brain from a computational to a connectionist model.

Complex: Dynamic nonlinear system of language is very complex because it meets both criteria of complexity. First, it is made of many different subsystems of phonology, morphology, lexicon, syntax, semantics, and pragmatics. Second, the language subsystems are interdependent. A change in any of them can culminate in a change in other systems (Larsen-Freeman, 1989, 1991b). The conduct of the whole springs out of the subsystem interactions.

Sensitive to initial conditions: Like other complex nonlinear systems, language shows dependence on initial conditions. UG may be the initial condition of complex human language - it includes specific universal principles to restrict the shape of human languages. For instance, there are a small number of core phonological patterns that apply to all whole languages, e.g. almost all world languages have voicing assimilation ofobstruents.

\subsection{Complex Nonlinear Systems and Second Language Acquisition}

When we compare second language acquisition with chaos/complexity theory, we find many amazing similarities. Both of them are complex systems. A metaphoric analogy will be used because according to Bowers (1990, 132) and Edge (1993), 'you do not understand something until you have the right metaphor to understand it".

Different theories, models and hypotheses have been proposed to explain SLA but no agreement has been reached up to now. Although both structuralists and mentalists are very popular and influential, a third perspective appeared when some important figures in applied linguistics began considering SLA as a chaos /complex (Larsen -Freeman, 1997) or ecological system (Van Lier, 1997).

The main objective of chaos theory to SLA is its solve the nature and nurture dichotomy as the learner can be seen of having cognitive capacities and also as an agent who has interaction with the other elements in his/her surrounding. There are the human interactions between teachers, classmates, and relatives, non-human interaction like school, books, music, media and films. When learners start learning they are in initial chaotic conditions and there are two opposing strong forces- first and second language, which produces a third force, the individual inter language.

\subsubsection{Identity, Agency and Autonomy}

Language is a necessary element for agency by our control over life or as "sociocultural mediated capacity to act" (Ahean, 2001).Identity and agency are two opposing sides on the same coin. The non-privileged often try to acquire more privileges and better identities by learning English, which is thought of as a bridge to a more successful life. As Norton (2001. p 166) states that, if learners invest in a second language, they will acquire a 
wider range of material and symbolic resources to increase their values in the social world.

\subsubsection{Affordance}

Affordance is depicted by Van Lier(2000, p 257) as demandes and requirements, opportunities and limitations, rejections and invitations, enablement and constraints". The dynamic collaboration between a learner and the other active agents in the SL learning complex system provides linguistic experiences. The non-prividged students don't have the same input or affordances as the priviledged do, they have to be more independent and autonomous and depende upon their activeness or agency in order to "connect their own selves to the world" (Van Lier, 2004a, $\mathrm{p}$ 147). According to complex theory, learners' autonomy or agency interacts with the ecological system (environment)and it may be affected by constraints and affordences(opportunities).

For example, a learner who lives in the Amazon forest without electricity;his/her affordances will be different froma learner who lives in New York.and his capacity will be limited by his/her environment.Despite human agency. SLA complex systems self-regulate and trasform themselves higher than the actual conscious willings of the learners due to human innate capacity to learn. In SLA very small interferences in the complex system may trigger astonishing experiences and change the learners' attitudes and behaviour. That is called the edge of chaos.

Dynamic: Both complex system and SLA are in a continuously dynamic process. In fact, recently, there has been a challenge of how to study the dynamism in the evolution of learner interlangauges (ILS). Dynamic features of ever-changing internal second language grammar cannot be explained by researcher's static rules of grammar. In fact, the most used 'target language' is misleading. There is no endpoint in language acquisition, and the target is always moving continuously.

Complex: The second language acquisition process is also complex. Many interacting variables determine the trajectory(route) of the developing interlanguage(IL).The source language, the target language ,the markedness or unmarkedness of the first language, the markedness or unmarkedness of the second language, the quantity and sort of input, the amount and type of collaboration and interaction in a an ecological perspective, amount and type of output, amount and type of feedback received, whether second language or foreign language is acquired in tutored or untutored environments, and so on. Also there are a lot of interacting variables that determine the successful second language acquisition process. For example: aptitude, age, sex, socio-psychology variables such as attitude, motivation, cognitive style, learning strategies, personality factors, interests, birth order and so on(Larsen-Freeman \& Long 1991). Therefore, the interaction between these various factors in an ecological system determines the ultimate effect.

Nonlinear: Learning language and linguistic items are nonlinear process. Second language learners do not learn one item completely and then move to another language item. In reality, learning curve for learning a single item is nonlinear. The curve is full of progress and going back and backsliding. Learning is brimmed with ups and downs. A good example is when language learners begin acquiring the past tense of regular and irregular verbs, These verbs are mastered increasingly at a lexical level, it means they learn one verb and its endings simultaneously. After further interaction and exposure to the target language chaos follows. It takes one more instancein the input of a past tense verb 'to break the camel's back'. While the interlanguage has many correct examples of past tense, a period of randomness of the -edfollowers, so the -ed is overgeneralized to irregular verbs, e.g.sitted, eated, sleeped. While earlier correct targets were being produced before. As the example was given, learners learn the past tense in a $U$-shape form. They first produce the correct form likeate or slept, and then they overgeneralized the regular -ed ending to all verbs and produce forms like eated or sleeped. Later in their interlanguage, they revert to the correct verb; ate or slept.

Open: If there is continuous input, the interlanguage system is self-organizing itself, and the chaos is related with past tense ending subsides gradually. The term that is used in language acquisition research is 'restructuring' of the interlanguage, which means return to order that occurs. Reverting to order is assisted by sensitivity of the system to feedback.

Sensitivity to feedback:"the absence of enough positive evidence in the environment or the explicit provision of negative evidence can help learner adapt their interlangauge grammar closer to that of target language users". (Larsen -Freeman, 2008). Fossilization occurs when there is no learning in a language and learners' grammar systems become closed and stop to a fixed point attractor.

By comparison, "in biology, the agents are organisms, the feedback is supplied by natural selection and the steady development of the models is called evolution. But in cognition, the agents are minds; the feedback comes from direct experience and teachers". (Waldrop, 1992, p 179)

Strange attractors: Although speakers' interlanguage of different first language are very similar, they are also constrained by the strange attractors of their first languages, which these strange attractors are stronger than English strange attractor, therefore English language pronunciation of a native speaker of French will be different from that of a native speaker of Persian. Organ (1995) believes that the promise of chaos/ complexity theory is very optimistic. Larsen-Freeman (2008) declared that his enthusiasm has caused him to exaggerate its scope of impact. 


\section{Promise of Chaos for the Future}

The science of complex systems is very modern and elaborate. It moves beyond the reductionist, linear approach that is the ordinary scientific thought of Newton. Complexity shows itself in chaotic systems in which many autonomous agents interact to produce phenomenon of emergence-which means a system that acts as more than its parts. The utility of chaos theory to humans may be astonishing. Complex theory enables experts to establish connections between multitudes of disciplines. Self regulation continue to emerge everywhere in the evolution of more complicated species and formation of planets and stars and even in the self-organization influences on the economy.

\section{Research Questions}

The following research questions will be investigated:

1. How is chaos theory explained in nature?

2. How is language viewed in chaos theory?

3. How is SLA expounded in chaos theory?

4. What are the educational implications of chaos/complexity theory?

5. What is the chaos-based classroom like?

6. What are the teachers' feedback and attitudes about chaos- theory based- teaching?

\section{Theoretical and Operational Definitions of the Key Terms}

Chaos theory: Chaos / complexity scientists study Complex nonlinear systems. They are interested in how disorder gives way to order, of how complexity arises in nature. (Larsen Freeman, 2008).To some physicists chaos is a science of process rather than state, of becoming rather than being. (Gleick, 1987).

Complex systems theory has also been widely proposed as an important new way to look at social and cognitive sciences, including language learning. (Larsen Freeman, 2008). One criticism of this new paradigm in the field of language learning is that no clear model of language learning based on complex systems theory has been developed. This paper considers the current state of language education, provides an overview of complex systems theory and then proposes a basic model of language learning based on the new paradigm. The paper concludes with some implications of adopting a complex systems model of language learning.(Bill Harshbarger,2007).

Teaching English as a foreign (TEFL) refers to teaching English to students whose first language is not English. TEFL usually occurs in the student's own country, either within the state school system, or privately, e.g., in an afterhours language school or with a tutor. TEFL teachers may be native or non-native speakers of English.
Second-language acquisition (SLA), second-language learning, or L2 acquisition, is the process by which people learn a second language. Second-language acquisition (SLA) also refers to the scientific discipline devoted to studying that process.

Second language refers to any language learned in addition to a person's first language; although the concept is named second-language acquisition, it can also incorporate the learning of third, fourth, or subsequent languages. Second-language acquisition refers to what learners do; it does not refer to practices in language teaching.

\section{Limitations and the Delimitation of the Study}

This study tries to implement the findings and principles of chaos theory into second language learning and foreign language learning. The study is a qualitative and attitudinal research. It aims to survey English language teachers' opinions of this new perspective of teaching and learning. So the findings cannot be generalized but it sheds more light on second and foreign language acquisition.

\section{Methodology}

The researcher held a workshop on the existence of chaos/complexity in English class. The workshop was developed to get familiarized with features of this theory and its applications. The class had a natural environment, for example, there were a lot of natural plants and flowers. There were some pictures of natural phenomena like trees, lighting images of clouds to depict features of chaotic and complex systems. A classic music was played at the beginning and the end of the class. Word Splash Poster and interesting interactive class resources that got learners' attention and motivated them when learning new words and definitions across all features of chaos theory were used. Finally the English language teachers' opinions were analyzed to see if their feedback supports or rejects the researcher's opinions.

\subsection{Participants}

The participants in this study were16 English language teachers, male and female. They were teachers teaching in junior and senior high schools.

\subsection{Instruments}

The main instrumentused in this study was questionnaire (open-ended questions) to know teachers' feedbacks and opinions about chaos-based language class. Some pictures illustrating natural phenomena were put on the wall and classic music was played at the beginning and the end of the class. Also Word Splash Poster was used to motivate teachers to learn the words and the definitions of chaos theory features. 


\subsection{Design}

This research is a qualitative and attitudinal survey research. The researcher is interested in understanding English teachers' opinions, feedback on using chaos-based language teaching and learning.

\section{Data Collection Procedure}

The data were collected at the end of workshop. In order to answer the last research questions by asking teachers' opinions and thought patterns and feedback and finally their feedback were analyzed to see if they support or reject the researchers' thoughts about chaos- based learning and teaching.

In this part, I will describe how I presented the chaos application in the classroom at a teacher-center. I attempted to delineate complexity in the dynamic classroom to teachers who might not have had any information of chaos/ complexity theory. In a short period of time (nearly 45 minutes), my objectives were to make the English teachers aware of application and connection with English teaching and to supply them a working and practical suggestion to implement chaos/complexity theory into their daily lesson plans.

\section{Data Analysis and Discussion}

The researcher first tried to explain nature's complex and different interconnectedness and to show the amazing evidences in many complex open living system .Language and learning a language are, as a matter of fact, natural systems. Every language and any beneficial language class show the behavior of a natural process by demonstrating features of chaos/complexity. By studying chaotic and complex system's features carefully the researcher has found a better recognition of the interconnectedness between the material, the students and English teacher. The teachers should pay close attention to what happen during his/her lessons and beless disappointed when seemingly random things take place and the class does not follow the exact predetermined plan.

Teachers can reduce their anxiety, students can be more interested in language learning and students' acquisition in English classroom will be facilitated. The researcher's aim is to show an application of chaos/complexity in a practical way which is based on many years of teaching experience. The applications of chaos and complexity theory will be very useful in classroom instruction if our teachers will began to incorporate it into their own teaching.

\subsection{My Familiarity with Chaos/Complex Theory}

My familiarity to chaos/complexity theory happened while I was studying for $\mathrm{Ph}$. D program. I became very interested in a fundamental book on this topic that was titled "Chaos: Making a New Science written" by James Gleick (2008) and another book that was amazingly interesting for me was "the Emerging Science at the Edge of Order and Chaos" written by M. Mitchell Waldrop (1992).

Language classroom is chaotic because the language teacher cannot control it completely and it is selforganizing because chaos (randomness) is only on the surface and basic pattern emerges as the time passes. A classroom like a human nature can be unpredictable and it is sensitive to initial conditions since apparently minute things can influence a person's behavior, which is demonstrated through using language. It is open because language learners need to be exposed to new and fresh input from the target culture and language. A language classroom, in addition, is feedback sensitive, because the students and language teachers benefit by collaborating and communicating with each other, and adaptive since the students must always cope with challenges in class and perform independently. An efficient language class has strange attractors to lead students' infinite learning potential and fractals, as students show the patterns and aims behind what the language teacher has planned.

The language classroom is a complex living organization with all the elements of chaos/complexity that are interacting and useful to the learning and teaching process. The teachers should not feel panic when they are not in total control. Moreover, they will have a deeper understanding of various possible results for any given activity.

Purpose of the workshop: the researcher tried to present a new way of classroom development to survey some underlying factors that lie behind the success or failure of a special activity/course.

It is relaxing for teachers to know that apparently random class happenings have an underlying order if we look at them from a suitable, whole view. This presentation for English teachers presented vocabularies that connect natural situations with English language accomplishment.

Set up and materials: The classroom was decorated with pictures of nature like beautiful dramatic weather phenomena, wonderful lighting strikes, cloud formations and hurricanes, because I aimed to associate nature (especially weather condition) to the class setting. In addition, I put flowers on the desk to increase the natural connection and played classic music at the begging of the session and at the end of the presentation to create an atmosphere of harmony and relaxation. I used different visual aids to present the vocabulary: a projector, white boat, and colorful handouts and slips of paper for two small groups. I used a word splash about chaos to permitevery English teacher chance to express his or her reactions and feelings about the "chaos "and I found the majority of their ideas about chaos to be negative at the beginning of the session. My chief aim was to allow English teachers gradually become relaxed with the natural existence of chaos in the class situation.

The English teachers were introduced to new terminology of chaos theory. They worked in pairs to 
match the features with their related definitions. The session was more "learner- centered" manner and I explained the vocabulary to activate their background knowledge. After wards, I showed them the answers on theprojector, explained the fifteen features and answered any question about the definitions. The slides also include classroom examples of each characteristic to build a connection between chaos and classroom.

Then I asked English teachers to form groups of four. Each group was given 10 strips of paper with examples of classroom context. They should decide which features of complexity theory were presented in each example given. After that the choices were discussed and there were different interpretations for most of examples.

I presented an overall picture of the chaos characteristics and its appearances in the activities. Finally, I requested the teachers' written feedback. As most teachers didn't have any prior knowledge of chaos/complex, I was very happy and surprised to find most of their written feedback and comments were positive and hopeful. Their opinions and feedback supported my research and consequently, I was enthusiastic and encouraged to research more about the associate of natural systems and the classroom.

\subsection{Teachers' Feedback}

Teacher 1: very wonderful and very good. I liked the occasion to see how well we understood the concepts liked the student-centered learning and lecture learning activities."

Teacher 2: It will be very useful to be able to see what's happening in the class and interpret it in new ways. I enjoyed interacting with activities and I thought the practical and presentational parts were very well balanced, thanks in deed.

Teacher 3: It caused me to think a lot. It was difficult to see pictures on the other side of room. I found your way of presentation very encouraging and interesting.

Teacher 4: The workshop was very interesting. But I expect you to talk about how to manage the chaos in the class. I did not understand some strange names of class features because they don't mean a thing. But thank you.

Teacher 5: Interesting concepts to understand classroom learning and dynamic class and concepts were presented interestingly. Thank you a lot.

Teacher 6: Terrific, interesting and great information. It really made us think and relax, not just sit and be passive. Now I want to get more information about chaos theory. Good teacher makes me want to learn more. Wow, great natural photos.

Teacher 7: Your presentation was excellent and very interesting for English teachers to review the learning/teaching process. The time was over very quickly because you involved us in interactive and pair work activities .You used wonderful music, flowers, visual aids and colors. Well-done, you made me think, rethink, involve and learn.

Teacher8: I thought the session was simple and concise and I understood how to put them (features of chaos in a foreign English class) into practice. The interaction and practical part were perfect.

Teacher 9: It opens interacting new perspective into classroom interaction and the working pattern that underline it. Pictures, posters lent a nice visual attention and also made the content more concrete and tangible. Terrific.

Teacher 10: Very stimulating. It keeps us on our toes! Well ready and organized. We were performing what we were talking about- learning by doing and experience. Rather just talking and listening about it. The photos of nature provided good examples and helped clarify concepts other than words. Excellent.

Teacher 11: It was fun to discover the chaos concepts and features. I didn't find out what is self-organizing. But the definition you have on your handout was understandable. I've got many new things to think about.

Teacher 12: The attempt to think about our classroom and understand its dynamic behavior by using an inductive method amused and interested me. Seeking to find out our great experiences in the classroom will be very deep but it's worth trying.

Teacher 13: This was a really brain- storming exercise and the concept of chaos is very new to me. Why didn't you explain the concept first in the class?

Teacher 14: Some of the concepts were puzzling to me. I particularly liked how you prepared pictures, flowers, music, etc. to produce a relaxing atmosphere to the presentation of chaos concepts. It was good to present it in the morning because we would have high level of intellectual interaction and discussion

Teacher 15: The workshop was conducted in a pleasant way. I really liked how groups participate in activities to connect and discuss features. They made us analyze and process the features and concepts in a deep and interesting way. We really experienced the basic concepts and now we have our own meanings.

Teacher 16: Music at the beginning set the mood interestingly. Really outstanding I want to know about chaos more, well-done, you used many sources: music, handouts, and pictures of nature, drawing or posters. Small groups of discussion were excellent.

\section{Conclusion}

Second and foreign language instruction is a challenging field since it requires learners to innovate and create their shape of self-expression. The teacher is accountable for his students' learning; however, in real situation there are some factors that are not under direct control of the teacher. When I look at the class as a natural environment, I think it is helpful to use chaos. Its features are sources of presenting new ways to class instruction and management, By using chaos features, I can be sure that I am presenting my students a real, natural context to develop their language skills. 
An English teacher may feel overwhelmed by different language theories, and teaching approaches. Chaos theory provides teachers a clearer general picture of what is happening in the class and also a structure to use the many educational concepts. For example, the concept of "student initiative" can be put into use, or the vocabulary should not be used in insolation. Teaching can benefit from a more holistic approach.

With chaos theory, a general structure connects many pedagogical concepts like student initiative, processing writing, feedback, etc. The teacher can feel sure to treat his or her class as a natural system and tolerate ambiguity.

Finally, what is important is the students' learning experience. Chaos theory produces a multidimensional classroom that students and facilities interact. The language class context is exactly mirrored by 15 features, which emphasized the elements in natural system. As a teacher, I understood the language process better; I can use that knowledge to make students feel more relaxed in the class and be capable to flourish as language learners. And they will learn how to learn, how to live pleasantly and will be empowered by English language.

\section{References}

[1] B. Harshbarger, Chaos, complexity and language learning. Language Research, 2007.

[2] B. Van Der Pol, Forced oscillations in a circuit with nonlinear resistance, (Reception with reactive triode), The London, Edinburgh, and Dublin Philosophical Magazine and Journal of Science, Vol.3, No.13, 1927, pp.65-80.

[3] C. Quirk, and A. Menezes, Do we need phrases? challenging the conventional wisdom in statistical machine translation. In Proceedings of the main conference on human language technology conference of the north American chapter of the association of computational linguistics, Association for Computational Linguistics, June 2006, pp.9-16.

[4] C. Taylor, Multiculturalism: Examining the Politics of Recognition, Princeton University Press, 41 William St., Princeton, NJ 08540, 1994.

[5] D. Larsen-Freeman, and L. Cameron, Complex systems and applied linguistics. Oxford University Press, 2008

[6] D. Larsen-Freeman, Chaos/complexity science and second language, 1997.

[7] D. Larsen-Freeman, M. H. Long, and Z. Jiang, An introduction to second language acquisition research, 1991, p.15.

[8] D. Larsen-Freeman, M. H. Long, and Z. Jiang, An introduction to second language acquisition research, London: Longman, 1991, pp.153-219.

[9] D. W. Organ, and K. Ryan, A meta - analytic review of attitudinal and dispositional predictors of organizational citizenship behavior, Personnel psychology, Vol.48, No.4, 1995, pp. 775-802.

[10] G. Lakoff, M Johnson, Philosophy in the flesh: The embodied mind and its challenge to western thought. Basic books, 1999.

[11] J. A.Given, and B. B. Mandelbrot, Diffusion on fractal lattices and the fractal Einstein relation, Journal of Physics, Mathematical and General, Vol.16, No.15), 1983.

[12] J. Gleick, Making a new science, Viking, New York, 1987.

[13] J. Hirshberg, S. J. Bame, and D. E. Robbins, Solar flares and solar wind helium enrichments, July 1965-July 1967.SolarPhysics, Vol.23, No.2,1972,pp.467-486.

[14] J. W. Berry, Immigration, acculturation, and adaptation. Applied psychology, Vol.46, No. (1),1997, pp.5-34.

[15] L. M. Ahearn, Language and agency, Annual review of anthropology, 2001,pp.109-137

[16] L. Sade-Beck, Internet ethnography: Online and offline, International Journal of Qualitative Methods,Vol.3, No.2, pp. 45-51.

[17] L. S. Norton, and J. C. W. Norton, Essay Feedback: How Can It Help Students Improve Their Academic Writing?2001.

[18] L. Van Lier, The ecology and semiotics of language learning. Kluwer Acad. Publ,2004.

[19] M. M. Waldrop, Complexity: The emerging science at the edge of order and chaos(Vol. 12), New York: Simon \& Schuster, 1992.

[20] P. M. Churchland, Matter and consciousness: A contemporary introduction to the philosophy of mind, The MIT press, 1988.

[21] R. B.Smith, On severe down slope winds. Journal of the atmospheric sciences, Vol.42, No.23,1985,pp.2597-2603.

[22] S. G. Thomason, and T. Kaufman, Language contact, creolization, and genetic linguistics, University of California Press, 1991 .

[23] W. B. Arthur, Complexity and the economy.science,1999, pp.107-109.

[24] W. E. Rutherford, Second language grammar: Learning and teaching, London: Longman,1987, p. 191.

[25] W. Von Humboldt, On the Historian's Task. History and theory, Vol.6, No.1,1967, pp.57-71 